\title{
A PRODUÇÃO DA ANPED SOBRE PROFESSORES INICIANTES E GRUPOS COLABORATIVOS EM EDUCAÇÃO MATEMÁTICA (2000-2015)
}

\author{
LA PRODUCCIÓN DE LA ANPED SOBRE PROFESORES INICIANTES Y GRUPOS \\ COLABORATIVOS EN EDUCACIÓN MATEMÁTICA (2000-2015)
}

\section{ANPED'S PRODUCTION ABOUT INITIATING TEACHERS AND COLLABORATIVE GROUPS IN MATHEMATICAL EDUCATION (2000-2015)}

\author{
Klinger Teodoro CIRÍACO ${ }^{1}$ \\ Maria Raquel Miotto MORELATTI ${ }^{2}$
}

RESUMO: Analisar a produção do conhecimento sobre a tendência investigativa dos trabalhos publicados nas reuniões anuais da Associação Nacional de Pós-Graduação e Pesquisa em Educação - ANPED- constitui-se foco central deste artigo. Para este fim, recorre-se a uma metodologia do tipo estado da arte na tentativa de caracterizar a produção do conhecimento "de" e "sobre" Educação Matemática e Formação de Professores no período de 2000 a 2015 a partir dos descritores "Processos Formativos e Aprendizagem da Docência", "Dificuldades de Professores Iniciantes", "A Formação do Professor e o Ensino de Matemática" e "Contextos de Colaboração Docente". A realização deste procedimento se justifica pela necessidade conhecer, de forma mais abrangente, o que tem sido realizado em termos de pesquisas acadêmicas acerca da temática para validação de uma proposta de doutoramento em educação. Da análise de dados, conclui-se que existe uma lacuna na produção do conhecimento quando se trata de estudar práticas colaborativas que visam articular professores de diferentes níveis de ensino em relação à Matemática, o que reforça a necessidade da implementação de iniciativas desta natureza.

PALAVRAS-CHAVE: Estado da arte. Educação matemática. Formação de professores. Grupos colaborativos. Iniciação à docência.

RESUMEN: El análisis de la producción del conocimiento sobre la tendencia investigativa de los trabajos publicados en las reuniones anuales de la Asociación Nacional de Postgrado e Investigación en Educación - ANPED- constituye un foco central de este artículo. Para este fin, se recurre a una metodología del tipo estado del arte en el intento de caracterizar la producción del conocimiento "de" y "sobre" Educación Matemática y Formación de Profesores en el período 2000 a 2015 a partir de los descriptores "Procesos Formativos y "Aprendizaje de la Docencia", "Dificultades de Profesores Iniciantes", "La Formación del Profesor y la Enseñanza de Matemáticas" y "Contextos de Colaboración Docente". La realización de este procedimiento se justifica por la necesidad de conocer, de forma más amplia, lo que se ha

${ }^{1}$ Universidade Federal de São Carlos (UFSCar), São Carlos - SP - Brasil. Professor Adjunto do Departamento de Teorias e Práticas Pedagógicas (DTPP) do Centro de Educação e Ciências Humanas (CECH). Docente Permanente do Programa de Pós-Graduação em Educação Matemática do Instituto de Matemática da UFMS. Doutor em Educação (UNESP). ORCID: https://orcid.org/0000-0003-1694-851X. E-mail: ciriacoklinger@gmail.com ${ }^{2}$ Universidade Estadual Paulista (Unesp), Presidente Prudente - SP - Brasil. Professora Assistente Doutora do Departamento de Matemática e Computação (DMC) e atualmente coordenadora do Programa de Pós-Graduação em Educação (PPGE) da Faculdade de Ciências e Tecnologia (FCT). ORCID: https://orcid.org/0000-0001-57123237. E-mail: maria.raquel@unesp.br

RPGE- Revista on line de Política e Gestão Educacional, Araraquara, v. 24, n. 2, p. 536-553, maio/ago. 2020. e-ISSN: 1519-9029. 
realizado en términos de investigaciones académicas acerca de la temática para validación de una propuesta de doctorado en educación. En el análisis de datos, se concluye que existe una laguna en la producción del conocimiento cuando se trata de estudiar prácticas colaborativas que apuntan a articular profesores de diferentes niveles de enseñanza en relación a la Matemática, lo que refuerza la necesidad de la implementación de iniciativas de esta naturaleza.

PALAVRAS-CLAVE: Estado del arte. Educación matemática. Formación de profesores. Grupos colaborativos. Iniciación a la docencia.

ABSTRACT: The purpose of this article is to analyze the knowledge production about the investigative tendency of the works published in the annual meetings of the National Association of Postgraduation and Research in Education. For this, a state-of-the-art methodology is used to characterize the production of knowledge about Mathematics Education and Teacher Training in the period from 2000 to 2015. The descriptors used were "Formative Processes and Teaching Learning", "Beginner Teacher Difficulties", "Teacher Training and Teaching Mathematics" and "Teaching Collaboration Contexts". This procedure is justified because of the need to know what has been done in terms of academic research on the subject for validation of a doctoral proposal in education. From data analysis, it is concluded that there is a gap in the production of knowledge in the study of collaborative practices that aim to articulate teachers of different levels of teaching in relation to Mathematics, which reinforces the need to implement initiatives of this nature.

KEYWORDS: State of the art. Mathematical education. Teacher training. Collaborative groups. Introduction to teaching.

\section{Introdução}

A formação de professores constitui-se em uma temática de estudos e pesquisas profícua e necessária nos últimos anos. Compreender a produção do conhecimento acerca deste assunto, especificamente, em relação à formação, iniciação profissional e as práticas de colaboração, seja no campo da Pedagogia e/ou da licenciatura em Matemática, foco deste artigo.

A justificativa para tal abordagem diz respeito à questão de que este trabalho encontrase vinculado a uma pesquisa mais alargada, em nível de doutorado, em que o objetivo fora realizar um mapeamento inicial na tentativa de validar a proposta de tese ${ }^{3}$ defendida no Programa de Pós-Graduação em Educação na Faculdade de Ciências e Tecnologia da Universidade Estadual Paulista - FCT/UNESP, Presidente Prudente-SP.

Dessa maneira, a discussão que segue procura demarcar a formação de professores enquanto campo investigativo em nosso país e, posteriormente, destacar, com base na produção

${ }^{3}$ Orientada pela Profa. Dra. Maria Raquel Miotto Morelatti.

RPGE- Revista on line de Política e Gestão Educacional, Araraquara, v. 24, n. 2, p. 536-553, maio/ago. 2020. e-ISSN: 1519-9029. DOI: https://doi.org/10.22633/rpge.v24i2.13228 
do conhecimento, elementos que justificam as escolhas e caminhos trilhados para a constituição de uma proposta de pesquisa desenvolvida em um grupo de trabalho colaborativo com professoras que ensinam Matemática em início de carreira no município de Naviraí, interior do Estado de Mato Grosso do Sul - MS.

\section{Fincando estacas: o procedimento metodológico empregado para o levantamento}

O princípio metodológico adotado aqui se refere à metodologia do tipo Estado da Arte, com o objetivo de identificar a tendência investigativa dos estudos publicados no período de 2000 a 2015 nas reuniões anuais da Associação Nacional de Pós-Graduação e Pesquisa em Educação - ANPED ${ }^{4}$.

De acordo com Morosini e Fernandes (2014, p. 155), o estado do conhecimento referese a um tipo de pesquisa que se define pela “[...] identificação, registro, categorização que levem à reflexão e síntese sobre a produção científica de uma determinada área, em um determinado espaço de tempo $[\ldots]$ ".

A consulta realizada ocorreu nos grupos de trabalhos "Formação de Professores" (GT 08) e "Educação Matemática" (GT 9) e teve como base encontrar artigos ${ }^{5}$ que debatessem as seguintes temáticas: "Processos Formativos e Aprendizagem da Docência", "Dificuldades de Professores Iniciantes" e "Contextos de Colaboração Docente".

Procedeu-se assim com a leitura de todos os textos dos GTs, na perspectiva de encontrar os que melhor se encaixassem no perfil do trabalho da pesquisa de doutorado a ser desenvolvida pelo autor deste artigo.

Ao trabalhar os artigos, procurou-se identificar lacunas na produção do conhecimento sobre a formação de professores que sustentassem a proposta de desenvolvimento da tese apresentada ao Programa de Pós-Graduação em Educação da FCT/UNESP: a constituição de um grupo de trabalho colaborativo com professoras iniciantes da área pedagógica (licenciadas em Pedagogia) e da área específica (licenciadas em Matemática).

${ }^{4}$ Esse levantamento inicial foi realizado predominantemente nessa base de dados, uma vez que a mesma é um encontro nacional e abarca diferentes regiões brasileiras.

${ }^{5}$ Todos os trabalhos foram agrupados nas dimensões mencionadas, independentemente de qual GT o texto tenha sido publicado. 


\section{O que dizem as pesquisas sobre professores iniciantes e grupos colaborativos?}

Apresenta-se como objetivo desta seção um panorama dos trabalhos publicados no Brasil em relação à formação docente, a partir de eixos centralizadores que procuram caracterizar a predominância da produção do conhecimento acadêmico, acerca da aprendizagem da docência, do ensino de Matemática, mas também do contexto colaborativo instituído com base em dinâmicas de interação entre professores e pesquisadores a partir de propostas de intervenção no ambiente escolar.

Após o mapeamento no portal da ANPED, foi organizado um quadro que ilustra a tendência das pesquisas no período circunscrito para o levantamento:

Quadro 01 - Tendência investigativa dos trabalhos sobre a formação de professores publicados nas reuniões anuais da ANPED (2000-2015)

\begin{tabular}{|c|c|c|c|}
\hline & \multicolumn{3}{|c|}{ TEMÁTICA DA PESQUISA } \\
\hline \multirow{2}{*}{$\begin{array}{l}\mathbf{A} \\
\mathbf{N} \\
\mathbf{O}\end{array}$} & $\begin{array}{l}\text { Processos formativos e } \\
\text { aprendizagem da } \\
\text { docência }\end{array}$ & $\begin{array}{l}\text { Dificuldades de professores } \\
\text { iniciantes }\end{array}$ & $\begin{array}{c}\text { Contextos de colaboração } \\
\text { docente }\end{array}$ \\
\hline & \multicolumn{3}{|c|}{ Número de trabalhos publicados } \\
\hline 2000 & 6 & - & - \\
\hline 2001 & 1 & 1 & 3 \\
\hline 2002 & 1 & - & 1 \\
\hline 2003 & - & - & 1 \\
\hline 2004 & - & 1 & 3 \\
\hline 2005 & 4 & 3 & 1 \\
\hline 2006 & 5 & - & 2 \\
\hline 2007 & 3 & - & 2 \\
\hline 2008 & 8 & - & 1 \\
\hline 2009 & 5 & - & 2 \\
\hline 2010 & 8 & 1 & 1 \\
\hline 2011 & 6 & - & 1 \\
\hline 2012 & 6 & - & 2 \\
\hline 2013 & 5 & 1 & 2 \\
\hline 2015 & 6 & 2 & 5 \\
\hline Total & 64 & 9 & 27 \\
\hline TOTA & URAL DE TRABALHOS & & 100 \\
\hline
\end{tabular}

Fonte: Elaborado pelo autor a partir de dados das reuniões anuais da ANPED, 2015. 
De forma geral, os textos encontrados nas reuniões incidem em discussões sobre a formação docente e a constituição da prática pedagógica, seja a nível inicial ou contínua.

Sobre a temática "processos formativos e aprendizagem da docência", interessa-nos os que procuraram discutir aspectos sobre o aprender a ensinar Matemática e caracterizar a fase inicial da docência. Dentre os 64 estudos, apenas 10 artigos serviram para perceber melhor os pontos que estão na base da investigação nos últimos anos: a) os que problematizam a relação entre a formação e o ingresso na carreira como, por exemplo, Nono e Mizukami (2006), Rocha (2004) e; b) aqueles que procuram compreender o movimento da aprendizagem da docência no ensino de Matemática, experiências presentes em Lopes (2005), Megid e Fiorentini (2010), Silva e Cedro (2015).

Em relação às "dificuldades de professores iniciantes" destaco a presença do menor número de estudos, o que demonstra a necessidade de investimentos em pesquisas que visam identificar e trabalhar com os professores as suas necessidades de formação nos primeiros anos da docência. Nesta perspectiva, descrevo mais detalhadamente estes estudos por revelarem proximidade com os objetivos da construção da tese de doutoramento que contém a discussão presente neste artigo.

Dos trabalhos encontrados, Gama e Gurgel (2001) caracterizaram sentidos e dilemas de professores de Matemática em início de carreira, com o objetivo de apresentar a transição da formação inicial para o ingresso na profissão. A ausência de discussões sistemáticas sobre o tema, em específico da iniciação à carreira no ensino de Matemática, mobilizou as autoras a aproximarem-se desse objeto de estudo.

Os procedimentos metodológicos adotados pautaram-se em múltiplas estratégias “[...] como histórias de vida, questionários semiabertos e outros registros escritos [...]" (GAMA; GURGEL, 2001, p. 04). O universo pesquisado diz respeito a quatro docentes egressos do curso de licenciatura em Matemática, sendo dois homens e duas mulheres e, destes, dois eram professores convocados e dois concursados.

Para as autoras, os sentimentos e dilemas dos docentes, confirmaram aspectos apontados pela literatura sobre esse momento da vida docente, uma vez que, a partir dos dados foi possível constatar a presença de dificuldades no processo de socialização no ambiente escolar, o que contribuiu para o isolamento do professor, dilemas decorrentes da indisciplina por parte dos alunos e dificuldades com a organização do conteúdo matemático.

A conclusão dessa pesquisa apontou para a necessidade da criação de contextos de apoio ao professor novato, denotando que o mesmo precisa de uma referência, para saber construir processos reflexivos para se desenvolver profissionalmente (GAMA; GURGEL, 2001). 
Rocha (2004), em sua dissertação de mestrado, discutiu como se configura a aprendizagem da docência de uma professora doutora iniciante, que atuava nas séries iniciais do Ensino Fundamental. Para a realização da pesquisa, a autora contou com dados obtidos a partir da " [...] escrita de diário reflexivo elaborado pela professora participante, com a intenção de conhecer como ela construiria o início de sua experiência docente durante o seu primeiro ano de atuação profissional" (ROCHA, 2004, p. 01). Para além disso, a pesquisadora teve dois encontros com a colaboradora do estudo, para problematizar algumas situações descritas no diário de reflexão.

Os resultados apontaram que, apesar do alto nível da formação da professora iniciante, os anos de estudo e investigação no campo educacional, a conclusão de seu doutorado pouco contribuiu para o exercício profissional da docência e as dificuldades centrais no seu trabalho colidiam com a heterogeneidade da sala de aula, o estabelecimento de regras da mesma com os alunos e com a indisciplina na turma superlotada (ROCHA, 2004). Todavia, destaca-se que apesar dos desafios iniciais da carreira, a docente relatou que "[...] não conseguiria superar tudo o que passou se não tivesse o embasamento teórico acumulado durante a sua vida acadêmica, reconhecendo o valor de sua formação profissional" (ROCHA, 2004, p. 03).

Sem dúvida, isso demonstra que a formação docente é um processo contínuo e que os professores sempre estarão em movimento de aprendizagens.

Semelhante ao estudo de Gama e Gurgel (2001), também Rocha e Fiorentini (2005) analisaram a constituição do ser professor de Matemática na fase de iniciação. O objetivo dos autores residiu em verificar como “[...] o professor de Matemática, na transição de aluno a professor, se constitui profissionalmente e, em particular, compreender como acontece o processo de mobilização de seus saberes adquiridos ao longo da vida [...]" (ROCHA; FIORENTINI, 2005, p. 01), sobretudo, na licenciatura, durante os primeiros anos de exercício da docência.

A pesquisa em questão teve duas fases, sendo que a primeira ocorreu a partir do contato com um grupo de licenciados em Matemática da Universidade Estadual de Campinas UNICAMP - por meio da aplicação de um questionário, em que se verificou quais eram os professores que estavam em atividade. Na segunda etapa, realizou-se o contato com dois docentes, para um estudo de caso mais aprofundado.

Os instrumentos de coleta de dados, para a obtenção das informações necessárias para a realização do estudo, foram: entrevistas semiestruturadas, observação de aulas, registros (áudio/vídeo) e o diário de campo da pesquisadora. Neste contexto, como os sujeitos foram dois professores, foi possível identificar elementos importantes da história de cada docente e que 
contribuíram para o processo de reconstituição dos saberes da docência em Matemática na fase inicial da profissão.

Ainda para os autores, outra instância fundamental para a formação e o desenvolvimento profissional dos professores é o contexto de reflexão e compartilhamento das experiências, dado frequente nas respostas dos recém-licenciados participantes da pesquisa, que foram propiciados no contexto do curso de Matemática nas disciplinas de Prática de Ensino e Estágio Supervisionado (ROCHA; FIORENTINI, 2005).

Essa situação particular, da formação desses professores iniciantes, contribuiu para a reconstituição dos seus saberes e também para o enfrentamento dos sentimentos presentes na fase de inserção.

A pesquisa de Corsi (2005) analisou situações difíceis enfrentadas por duas professoras dos anos iniciais durante os primeiros anos da docência. No referido estudo, a autora teve como fonte de coleta de dados, registros em diários reflexivos, entrevistas mensais elaboradas a partir das informações contidas na escrita das docentes.

Dentre os aspectos que dificultaram esse período de entrada na carreira, as professoras mencionaram o comportamento dos alunos em relação à disciplina e as formas de organização e abordagem conceitual com os conteúdos, embora de forma sutil, mas isso fez-se presente nos relatos escritos e, para Corsi (2005), a explicação para essa questão passa pelo fato de que as professoras iniciantes parecem não ter consciência que não dominam determinados conteúdos escolares.

De modo comum, os resultados da pesquisa indicaram que o trabalho com narrativas escritas, apresenta-se como uma possibilidade metodológica investigativa importante e promissora, na medida em que permite, ao professor, explicitar seus pensamentos e ações em um ato de reflexão sobre a prática escolar. Para Corsi (2005), esse dado implica num processo de ressignificação da experiência, uma vez que, o professor pode retomar o seu trabalho, tentando sanar as lacunas anteriores observadas.

Lima (2005) desenvolveu uma investigação que teve como base caracterizar dilemas "[...] dos professores do Ensino Fundamental (séries iniciais) e compreender como os conflitos/dificuldades no desenvolvimento das suas práticas, podem, ou não, se converter em saberes para a aprendizagem da docência" (LIMA, 2005, p. 01). As colaboradoras do estudo, foram professoras com até seis anos de experiência e que participavam do curso de Pedagogia para professores em exercício.

A autora trabalhou com os memoriais das estudantes e entrevistas semiestruturadas como fonte direta de informações para a realização da pesquisa. 
Para Lima (2005, p. 05), a fase de iniciação ao ensino pode ser considerada um momento “[...] de tensões/conflitos/dilemas em contextos que podem ser conhecidos ou não, durante os quais os professores deveriam adquirir conhecimento profissional, além de poder manter certo equilíbrio pessoal”.

Contudo, no momento da publicação do texto, a investigação ainda não estava finalizada, mas apontava para a possibilidade de favorecer uma compreensão mais detalhada, dessa fase da vida do professor, sobre o aprender a ensinar.

Carneiro e Passos (2010) apresentam resultados de uma investigação de mestrado em que o objetivo foi compreender "[...] não apenas as contribuições da Licenciatura em Matemática para a utilização das Tecnologias da Informação e Comunicação nas aulas dos professores em início de carreira, mas também as características dessa fase docente [...]" (CANEIRO; PASSOS, 2010, p. 01).

O estudo justifica-se, pelo fato de ser necessário compreender como professores de Matemática, egressos de uma universidade pública, estavam formados para lidar com as tecnologias no contexto educacional. Os autores elaboraram um plano de pesquisa que visou dois momentos de aplicação de questionários e, outro com a realização de entrevistas semiestruturadas com docentes que se dispuseram em contribuir voluntariamente. Os sujeitos participantes foram quatro professores de Matemática que declararam, em resposta aos questionários, trabalhar com tecnologias nas salas de aula.

As características da utilização das TICs foram identificadas como sendo desafiadoras durante a iniciação à docência, uma vez que, para os professores, utilizar o computador nas aulas é difícil porque "[...] os alunos veem o computador como um objeto de entretenimento e lazer [...]" (CARNEIRO; PASSOS, 2010, p. 07).

Esta situação foi descrita pelos docentes pesquisados como exaustiva, porque a empolgação e entusiasmo inicial dos alunos acabavam por prejudicar os objetivos pedagógicos da proposta de atividade, nas primeiras vezes em que utilizavam a tecnologia.

Em conclusão, os autores afirmam que, com a pesquisa foi possível levantar experiências diversificadas, vivenciadas pelos professores nas quais a tecnologia foi utilizada de diversas formas, de modo que os alunos se sentissem mais motivados na aprendizagem. Para os professores iniciantes, os resultados positivos, posteriores ao processo de utilização desses recursos, contribuiu na superação das dificuldades para a permanência na profissão.

Em suma, os dados sinalizaram que a tecnologia é uma fonte potencializadora de aprendizagem e que, quando o docente tem o domínio dela, é possível fazer com que os alunos explorem, levantem conjecturas, testem hipóteses, entre outros (CARNEIRO; PASSOS, 2010). 
Duarte (2013) dissertou em uma proposta de estudo de mestrado, em desenvolvimento, que tem como objetivo compreender quais as implicações da cultura escolar na constituição do profissionalismo dos docentes iniciantes. A metodologia adotada insere-se nos estudos qualitativos em educação, a autora observou aulas e acompanhou oito professores a partir de reuniões com um grupo focal.

A proposta direciona-se para a compreensão das dificuldades das professoras para o tornar-se professor, ao constituírem especificidades da ação docente.

Gariglio (2015) analisou processos de iniciação profissional de licenciados em Educação Física. O autor procurou identificar percepções e movimentos de aprendizagens durante os primeiros anos da carreira e, para isso, os instrumentos de coleta de dados foram entrevistas e análises de casos de ensino, a partir de registros escritos dos professores.

As conclusões apontaram para “[ [...] o caráter situado da iniciação à docência no qual se podem verificar singularidades de experiências e percepções sobre esse ciclo de desenvolvimento profissional" (GARIGLIO, 2015, p. 01). Nesta direção, tal caráter diz respeito ao contexto da inserção desses professores, que se demonstrou ligado fortemente ao campo das disciplinas em que atuam (GARIGLIO, 2015).

Em uma nova publicação, Duarte (2015) destacou os resultados finais da sua pesquisa. Desta vez, a autora apresentou a constituição do tornar-se professor no início da docência e as especificidades dessa ação.

Os dados finais destacaram que, para as professoras, existe incompatibilidade entre a teoria e a prática, ou seja, na relação entre os conhecimentos adquiridos no curso de formação inicial e os saberes necessários para o exercício da carreira.

De acordo com Duarte (2015, p. 11), tal conflito ocorre porque as docentes têm a “[...] compreensão da teoria como algo que dever ser aplicado a uma realidade predefinida, que não se altera e que é constituída por modelos ideais". Esse conflito vivenciado, acaba por contribuir para o fortalecimento do sentido da experiência atribuída pelos professores para a constituição da prática pedagógica.

A produção do conhecimento sobre "contextos de colaboração docente" agrupam estudos voltados para experiências em grupos de estudos e pesquisas; estudos em projetos colaborativos de pesquisa-ação, pesquisa-intervenção e pesquisa-formação; culturas de desenvolvimento profissional docente e colaboração; questões ligadas à supervisão pedagógica e ao trabalho coletivo no espaço escolar e grupos colaborativos (FERREIRA, 2004; COSTA, 2006; GAMA; FIORENTINI, 2008; CRECCI; FIORENTINI, 2012; AZEVEDO, 2013). 
Os estudos que abarcam questões similares e que, de certa forma, contribuem para um melhor delineamento da tese apresentada neste texto, inscrevem-se nos trabalhos que discutiram culturas de desenvolvimento profissional, trabalho colaborativo na escola e grupos colaborativos.

Pesquisas como as de Gama e Fiorentini (2008), Nogueira, Almeida e Melim (2013), Mollica e Almeida (2015) procuraram caracterizar processos de iniciação à docência em ambientes de colaboração sob perspectivas metodológicas diferentes.

Dentre estes estudos, destaco Gama e Fiorentini (2008), por ser uma pesquisa com características próximas da proposta da tese que desenvolvi. No texto, os autores relataram resultados de uma pesquisa de doutorado em que o objeto de investigação foi $o$ desenvolvimento profissional de professores de Matemática iniciantes com o apoio de grupos colaborativos. Como recorte do estudo, no artigo em questão, apresentam-se as contribuições das interações nesse espaço formativo dos grupos para a constituição das identidades dos docentes.

A identificação dos grupos colaborativos, que tinham como integrantes docentes iniciantes, ocorreu a partir da aplicação de um questionário respondido por 60 sujeitos da região entre os municípios de Campinas e Ribeirão Preto/SP. Em análise das respostas, foi constatado a presença de 3 grupos $^{6}$ e selecionados, um participante de cada, para um estudo mais aprofundado.

Os grupos que subsidiaram a realização da tese tinham características comuns, centradas em investigação e reflexão sobre a prática docente com o intuito de "[...] construção de conhecimentos voltados ao desenvolvimento profissional e pessoal dos professores" (GAMA; FIORENTINI, 2008, p. 04).

Na conclusão, os autores sinalizaram que o espaço reflexivo, possibilitado pela inserção e atuação no grupo de estudo, configura-se como mecanismo de apoio para os professores iniciantes, pois proporciona ambientes de investigação sobre a própria prática pedagógica, tanto a nível individual quanto coletivo. Neste sentido, em síntese, é na interlocução com os outros que os professores de Matemática são "[...] influenciados e influenciam nesse processo de constituição das identidades individuais e coletivas no grupo" (GAMA; FIORENTINI, 2008, p. 09).

${ }^{6}$ Grupo de Sábado (GdS/FE-UNICAMP); Grupo de Educação Matemática (GEM/DEME-UFSCar); Grupo Colaborativo de Estudos em Educação Matemática (GCEEM/Diretoria Regional de Americana). 
Pesquisas como as de Soares e Pinto (2001), Ferreira (2004), Lopes (2004), Costa (2006), Crecci e Fiorentini (2012) e Azevedo (2013) discutiram também, o processo de colaboração na formação e prática do professor que ensina Matemática.

Nestes estudos, o trabalho colaborativo é descrito como sendo uma alternativa para a construção da autonomia e desenvolvimento profissional. Com isso, os grupos são a base investigativa para a elaboração de teorias sobre a cultura de comunidades docentes.

Ferreira (2004) analisou o desenvolvimento profissional e metacognitivo de professores de Matemática a partir da participação em um grupo de trabalho colaborativo. Esta pesquisa, de caráter qualitativo, propôs responder quais as contribuições da participação nesse grupo, constituído pela autora, que era voltado a aprofundar os saberes da profissão e processos de metacognição para a prática docente.

Os participantes do estudo trabalhavam na rede pública de ensino de Campinas/SP e a coleta de dados ocorreu a partir de encontros semanais, que eram gravados e, posteriormente, transcritos pela pesquisadora. Acompanharam-se algumas aulas dos professores e outros registros, como o roteiro de observação, que foram produzidos no período de um ano de trabalho de campo.

Os resultados demonstram que, os integrantes passaram por diversos momentos ao longo do ano de constituição e formação do grupo. Neste ambiente de colaboração, inicialmente, os professores esperaram uma postura mais passiva durante os encontros e, no decorrer do tempo, passaram a se integrar e a tomar decisões coletivas para o gerenciamento das propostas de reflexão, o que demonstrou o grande potencial do trabalho colaborativo no desenvolvimento profissional.

Contudo, Ferreira (2004) sinalizou que as aprendizagens nesse espaço foram diferentes para cada professora, dadas as características próprias de cada uma, ligadas à história de vida, formação, interesses e tempo de exercício do magistério. Para a autora, a experiência do grupo, mostrou-se ainda como um contexto catalisador de aprendizagem da docência, mas, nas conclusões, deixou um alerta de que trabalhos de natureza similar, podem apresentar limitação em decorrência do pouco espaço de tempo para as reflexões, uma vez que, nessa pesquisa, esse fator apresentou-se desfavorável, pois, ao final da tese, notou que apenas estava começando o processo com os professores.

Lopes (2004) trabalhou com um grupo de professoras da Educação Infantil no intuito de investigar o desenvolvimento profissional em relação à Matemática, mais especificamente, a Estatística e Probabilidade na infância. Na visão da autora, a contribuição do estudo reside em ampliar uma linha de investigação que “[...] tem clara a importância do trabalho em parceria 
com professores e a percepção da riqueza da aquisição do conhecimento coletivo" (LOPES, 2004, p. 02).

Nesta perspectiva, a pesquisa considerou que a participação das professoras, teria de ser uma opção que visasse contribuir com o desenvolvimento profissional das mesmas. A análise do conhecimento e da prática das docentes, seria resultado das informações de fontes diversificadas, organizadas a partir de problemas didático-pedagógicos relacionados ao ensino/aprendizagem da Estatística na Educação Infantil (LOPES, 2004).

A autora assume o posicionamento de que é importante o processo reflexivo, para a construção da autonomia e do trabalho colaborativo com os professores. Para tal, desenvolveu o estudo num grupo formado por ela e professoras participantes, nas quais buscou compreender a seguinte questão: “Que contribuições o estudo, a vivência e a reflexão sobre conceitos de estatística e probabilidade podem trazer para o desenvolvimento profissional e a prática pedagógica de um grupo de professoras da educação infantil?” (LOPES, 2004, p. 13, grifos da autora).

$\mathrm{Na}$ análise realizada, evidenciou-se que o movimento de reflexão, possibilitou a construção de novos saberes e conhecimentos profissionais específicos, ligados a conteúdos de combinatória, estatísticas e probabilidade, previstos pelo currículo. As professoras, produziram saberes da profissão de modo criativo e consciente, de forma a contribuir para a temática (LOPES, 2004).

Em suma, a pesquisa de formação contínua no ambiente de colaboração, mostrou que essa perspectiva de trabalho, permite o aprimoramento da prática docente e amplia a autonomia profissional, a partir da reflexão permanente do processo de ensino e aprendizagem.

Costa (2006) desenvolveu um estudo, a nível de doutorado, com características colaborativas, motivado pela pouca ênfase de estudos brasileiros em relação à utilização das Tecnologias de Informação e Comunicação (TICs), por professores de Matemática nas escolas públicas. Nessa pesquisa, o autor trabalhou com um projeto colaborativo de iniciação ao uso de tecnologias, numa escola do município de Tubarão/SC, em que os envolvidos foram professores de Matemática e o coordenador do projeto, no caso o pesquisador.

A experiência do estudo foi realizada com o intuito de verificar o que ocorre, no sentido de mudanças na cultura profissional quando um grupo colaborativo é constituído na escola, pelos professores, para a introdução das TICs na prática docente (COSTA, 2006). Foram elaborados estudos de caso "[...] associados a essa experiência de introdução das TICs na prática escolar das duas professoras: o estudo de caso de Joelsa; o estudo de caso de Cida e o estudo 
de caso do movimento de constituição, trabalho e consolidação do grupo" (COSTA, 2006, p. 08).

No decorrer do tempo, com encontros semanais e nos círculos de estudos propostos, a partir de dinâmicas de cursos à distância e discussões presenciais posteriores, o grupo foi adquirindo características colaborativas.

Segundo o autor, a perspectiva de trabalho colaborativo rompeu com o individualismo da profissão e empoderou as professoras participantes. “Assim, apoiadas pelo grupo ousaram, incorporando as TICs no trabalho docente e na educação dos alunos" (COSTA, 2006, p. 11).

Muitas foram as contribuições, para a utilização das tecnologias no grupo, pois as interações desencadearam mudanças da cultura dos professores na medida em que, perceberam novas configurações na sua prática pedagógica com a utilização das TICs. A pesquisa mostra que experiências de trabalho colaborativo envolvendo professores e pesquisadores em movimento de reflexão sobre a prática, contribuem para o desenvolvimento profissional dos participantes.

Crecci e Fiorentini (2012) discutiram a constituição da profissionalidade docente, em comunidades investigativas com base em grupos colaborativos. Deste modo, para a pesquisa, os autores consideraram grupos “[...] que refletem e investigam sobre a própria prática pedagógica, utilizando diferentes modalidades de pesquisa ou análise sistemática da prática, como comunidades de investigação" (CRECCI; FIORENTINI, 2012, p. 01).

O objetivo do estudo foi compreender a aprendizagem, desenvolvimento profissional e a constituição da profissionalidade, a partir de indícios da participação de professores em grupos colaborativos que investigam processo de ensino e aprendizagem. Os envolvidos foram professores que ensinam matemática e participam dessas comunidades de investigação.

A coleta de dados realizou-se em três fases: $1^{\text {a }}$ ) envio de questionários por e-mail para professores participantes de grupos colaborativos, que foram identificados a partir de textos publicados em anais congressos e/ou livros; $2^{\mathrm{a}}$ ) entrevista com quatro professores integrantes desses grupos, com o objetivo de aprofundar a investigação em relação à constituição da profissionalidade nesses espaços coletivos e; $3^{\mathrm{a}}$ ) observação participante com registros no diário de campo da pesquisadora, assim como da participação nas reuniões de estudo dos grupos colaborativos em que os professores entrevistados eram integrantes.

Nesta última fase da pesquisa de campo, o intuito foi “[...] coletar informações que permitam descrever as dinâmicas de trabalho e estudo dos grupos colaborativos [...]" (CRECCI; FIORENTINI, 2012, p. 04). 
O estudo de doutorado em questão, encontrava-se, quando do momento da publicação na ANPED, em fase final de coleta e início da análise de dados. Nesta perspectiva, alguns resultados parciais indicaram evidências de que, os grupos colaborativos têm suscitado elementos que permitem a constituição dos conhecimentos de investigação sobre a prática pedagógica dos professores que deles participam (CRECCI; FIORENTINI, 2012).

Outra questão relevante é que, no caso pesquisado pelos autores, o constituir-se professor parece estar diretamente ligado à análise da prática, uma vez que os integrantes dos grupos "[...] problematizam seus conhecimentos e deixam de ser consumidores acríticos de ideias gestadas por especialistas" (CRECCI; FIORENTINI, 2012, p. 04), ou seja, ganham maior autonomia.

Azevedo (2013), no último estudo encontrado e desenvolvido com grupos de professores, descreve a proposta de doutorado, defendida na Universidade Federal de São Carlos - UFSCar -, em que relatou as aprendizagens de professoras da Educação Infantil, numa experiência de formação continuada, envolvendo o conhecimento matemático.

O grupo foi constituído pela pesquisadora e denominou-se "Outros Olhares para a Matemática" - GEOOM. As integrantes, 39 docentes da Educação Infantil, atuavam na rede municipal de São Carlos/SP, se reuniam e conviviam, entre os anos de 2010 e 2012, por cinco semestres consecutivos (AZEVEDO, 2013).

A coleta de dados foi possível a partir das narrativas orais e escritas das professoras, das informações do diário de campo da pesquisadora e de um questionário aplicado ao término da experiência formativa proposta. O gerenciamento das ações, pautou-se nos estudos teóricos sobre os conteúdos e em discussões reflexivas sobre a prática docente ao longo de todo processo.

Com a intervenção realizada, verificou-se indícios da potencialidade das interações no grupo para a prática das professoras, para o conhecimento específico dos conteúdos matemáticos e dos recursos metodológicos para sua abordagem. $\mathrm{O}$ debate das questões metodológicas no espaço de colaboração do grupo, não se desvinculou dos aspectos conceituais das propriedades matemáticas, uma vez que “[...] só a técnica não dá conta da complexidade do processo de ensinar e aprender matemática na infância” (AZEVEDO, 2013, p. 15).

As conclusões apontaram que, formas de ensino e aprendizagem de matemática no campo da Educação Infantil, foram constituídas pelas professoras e redirecionados de forma coletiva no espaço do GEOOM, sempre com respeito às especificidades teórico-metodológicas de cada docente, numa perspectiva de reflexão sobre a prática pedagógica. 
Os resultados das pesquisas em contextos de colaboração docente, nos grupos colaborativos, retratam situações em que o espaço formativo possibilitado pelo compartilhamento e ressignificação das experiências oportuniza, ao professor, o desenvolvimento profissional e a autonomia. Esse elemento reforça a necessidade de investimentos de propostas que sejam desenvolvidas "com” os professores e não "sobre" eles.

Neste contexto investigativo, chamo atenção para o reduzido número de estudos relacionados às dificuldades dos professores iniciantes e ao trabalho colaborativo com professores que ensinam matemática, seja ele educador matemático ou pedagogo.

\section{Considerações finais}

Nos trabalhos analisados neste paper, observa-se que entre os 100 artigos, apenas 9 destinaram-se a discutir as dificuldades dos anos iniciais da docência e, destes, 3 abordaram questões sobre a docência em Matemática (GAMA; GURGEL, 2001; ROCHA; FIORENTINI, 2005; CARNEIRO; PASSOS, 2010). E, de 27 que se propuseram abordar processos de colaboração docente, 6 foram no campo da pesquisa em Educação Matemática.

Esta baixa proporcionalidade, reforça a relevância de propor uma pesquisa específica com professores iniciantes num grupo de trabalho colaborativo, que visa a interação, entre sujeitos com perfis de formação para o ensino de Matemática distinto, ou seja, um espaço de reflexão permanente sobre práticas docentes de Matemáticos e Pedagogos, uma vez que as pesquisas anteriores trabalharam, ora com grupos constituídos de matemáticos (FERREIRA, 2004; COSTA, 2006; GAMA; FIORENTINI, 2008), ora de pedagogos (LOPES, 2004; CRECCI; FIORENTINI, 2012; AZEVEDO, 2013).

Por outras palavras, não foi possível identificar ainda nenhum outro estudo, que tenha como objetivo a interação entre professores de Matemática e Pedagogos, característica essa que constituiu elemento central da tese que desenvolvi. Ao relacionarmos as iniciativas de valorização da carreira do magistério, é possível verificar que existem grandes preocupações, tanto em relação às propostas e programas de formação inicial quanto a continuada, mas, quando pensamos no período de indução, de inserção e permanência na carreira docente, existe um vácuo nas propostas governamentais e em algumas pesquisas, como se observa no levantamento realizado junto a base de dados da ANPED, o que sinaliza um certo abandono para esse período tão importante na constituição da identidade docente.

Tal fato apresenta mais um motivo para o recorte da temática em processos de pesquisa sobre o início da docência, na tentativa de caracterizar sentimentos particulares desse período. 
AGRADECIMENTOS: À Coordenação de Aperfeiçoamento de Pessoal de Nível Superior CAPES - pela concessão da Bolsa de Doutorado Sanduíche no Exterior, a qual contribuiu, sobremaneira, para o processo de elaboração da tese de doutorado do autor.

\section{REFERÊNCIAS}

AZEVEDO, P. D. de. O conhecimento matemático na Educação Infantil: o processo de formação continuada de um grupo de professoras. In: REUNIÃO ANUAL DA ANPED, 36., 2013. Goiânia. Anais [...]. Goiânia, GO, 2013. Disponível em:

http://36reuniao.anped.org.br/pdfs_trabalhos_aprovados/gt19_trabalhos_pdfs/gt19_3376_text o.pdf. Acesso em: 30 mar. 2015.

CARNEIRO, R. F.; PASSOS, C. L. B. Características do início de carreira de professores de Matemática, com a utilização das tecnologias da informação e comunicação. In: REUNIÃO ANUAL DA ANPED, 33., 2010. Caxambu. Anais [...]. Caxambu, MG, 2010. Disponível em: http://33reuniao.anped.org.br/33encontro/app/webroot/files/file/Trabalhos\%20em\%20PDF/G T19-6162--Res.pdf. Acesso em: 04 set. 2015.

CORSI, A. M. Professoras iniciantes: situações difíceis enfrentadas no início da prática docente no Ensino Fundamental. In: REUNIÃO ANUAL DA ANPED, 28., 2005. Caxambu. Anais [...]. Caxambu, MG, 2005. Disponível em: http://28reuniao.anped.org.br/. Acesso em: 20 mar. 2015.

COSTA, G. L. M. O trabalho colaborativo e as tecnologias de informação e comunicação na formação e na prática pedagógica do professor de Matemática: indícios de mudança da cultura docente. In: REUNIÃO ANUAL DA ANPED, 29., 2006. Caxambu. Anais [...]. Caxambu, MG, 2006. Disponível em: http://29reuniao.anped.org.br/trabalhos/trabalho/GT19-2234-Int.pdf. Acesso em: 02 jun. 2015.

CRECCI, V. M.; FIOREINTINI, D. A constituição da profissionalidade docente em comunidades de investigação - o caso dos grupos colaborativos. In: REUNIÃO ANUAL DA ANPED, 35., 2012. Porto de Galinhas. Anais [...]. Porto de Galinhas, PE, 2012. Disponível em: http://35reuniao.anped.org.br/images/stories/posteres/GT08/GT08-1341_int.pdf. Acesso em: 01 out. 2015.

DUARTE, S. M. C. A. A cultura escolar e suas implicações na profissionalidade de professores ingressantes. In: REUNIÃO ANUAL DA ANPED, 36., 2013. Goiânia. Anais [...]. Goiânia, GO, 2013. Disponível em:

http://36reuniao.anped.org.br/pdfs_posteres_aprovados/gt08_posteres_aprovados/gt08_3193_ texto.pdf. Acesso em: 20 ago. 2015.

DUARTE, S. M. C. A. Tornar-se docente: o início da carreira e o processo de constituição da especificidade da ação docente. In: REUNIÃO ANUAL DA ANPED, 37., 2015.

Florianópolis. Anais [...]. Florianópolis, SC, 2015. Disponível em: http://37reuniao.anped.org.br/wp-content/uploads/2015/02/Trabalho-GT08-4548.pdf. Acesso em: 01 out. 2015. 
FERREIRA, A. C. Analisando o desenvolvimento profissional e metacognitivo de professores de Matemática a partir de sua participação em um grupo de trabalho colaborativo. In: REUNIÃO ANUAL DA ANPED, 23., 2004. Caxambu. Anais [...]. Caxambu, MG, v. 1, 2004. Disponível em: http://27reuniao.anped.org.br/textosgt19.htm. Acesso em: 02 fev. 2015.

GAMA, R. P.; FIORENTINI, D. Professores de Matemática em início de carreira: identidades $\&$ grupos colaborativos. In: REUNIÃO ANUAL DA ANPED, 31., 2008. Caxambu. Anais [...]. Caxambu, MG, 2008. Disponível em: http://31reuniao.anped.org.br/1trabalho/GT194139--Int.pdf. Acesso em: 03, jul. 2015.

GAMA, R. P.; GURGEL, C. M. do A. Sentimentos e dilemas de professores de Matemática em início de carreira docente. In: REUNIÃO ANUAL DA ANPED, 24., 2001. Caxambu. Anais [...]. Caxambu, MG, 2001. Disponível em: http://24reuniao.anped.org.br/tp1.htm\#gt19, Acesso em: 12 jun. 2015.

GARIGLIO, J. A. Dilemas e aprendizagens profissionais de professores iniciantes de Educação Física. In: REUNIÃO ANUAL DA ANPED, 37., 2015. Florianópolis. Anais [...]. Florianópolis, SC, 2015. Disponível em: http://37reuniao.anped.org.br/wpcontent/uploads/2015/02/Trabalho-GT08-3524.pdf. Acesso em: 01 out. 2015.

LIMA, A. C. R. E. Aprendizagem da docência: dilemas profissionais dos professores iniciantes. In: REUNIÃO ANUAL DA ANPED, 28., 2005. Caxambu. Anais [...]. Caxambu, MG, 2005. Disponível em: http://28reuniao.anped.org.br/. Acesso em: 20 mar. 2015.

LOPES, A. R. L.V. Ensinar e aprender Matemática: alguns aspectos sobre a aprendizagem da docência na formação inicial de professores. In: REUNIÃO ANUAL DA ANPED, 28., 2005. Caxambu. Anais [...]. Caxambu, MG, 2005. Disponível em: http://28reuniao.anped.org.br/. Acesso em: 30 mar. 2015.

LOPES, C. A. E. Educação Matemática na infância: o desenvolvimento profissional de um grupo de professoras. In: REUNIÃO ANUAL DA ANPED, 27., 2004. Caxambu. Anais [...] Caxambu, MG, 2004. Disponível em: http://27reuniao.anped.org.br/gt19/t193.pdf. Acesso em: 13 jun. 2015.

MEGID, M. A. B. A.; FIORENTINI, D. As narrativas e o processo de aprendizagem docente. In: REUNIÃO ANUAL DA ANPED, 33., 2010. Caxambu. Anais [...]. Caxambu, MG, 2010. Disponível em:

http://33reuniao.anped.org.br/33encontro/app/webroot/files/file/Trabalhos\%20em\%20PDF/G T19-6348--Int.pdf. Acesso: 23 ago. 2015.

MOLLICA, A. J. P.; ALMEIDA, L. R. de. O professor especialista iniciante e o apoio do coordenador pedagógico. In: REUNIÃO ANUAL DA ANPED, 37., 2015. Florianópolis. Anais [...]. Florianópolis, SC, 2015. Disponível em: http://37reuniao.anped.org.br/wpcontent/uploads/2015/02/Trabalho-GT08-3806.pdf. Acesso em: 01 out. 2015.

MOROSINI, M. C.; FERNANDES, C. M. B. Estado do Conhecimento: conceitos, finalidades e interlocuções. Educação Por Escrito, Porto Alegre, v. 5, n. 2, p. 154-164, jul./dez. 2014. Disponível em: http://revistaseletronicas.pucrs.br/ojs/index.php/porescrito/article/view/18875/12399. Acesso em: 30 nov. 2015. 
NOGUEIRA, E. G. D.; ALMEIDA, O. A.; MELIM, A. P. G. A docência expressa nas visões e nas vozes de professores iniciantes e acadêmicos: revelações na/da pesquisa-formação. In: REUNIÃO ANUAL DA ANPED, 36., 2013. Goiânia. Anais [...]. Goiânia, GO, 2013. Disponível em:

http://36reuniao.anped.org.br/pdfs_trabalhos_aprovados/gt08_trabalhos_pdfs/gt08_3327_text o.pdf. Acesso em: 09 jun. 2015.

NONO, M. A.; MIZUKAMI, M. G. N. Processos de formação de professoras iniciantes. In: REUNIÃO ANUAL DA ANPED, 29., 2006. Caxambu. Anais [...]. Caxambu, MG, 2006. Disponível em: http://29reuniao.anped.org.br/trabalhos/trabalho/GT08-1868--Int.pdf. Acesso em: 18 ago. 2013.

ROCHA, G. A. O início da carreira docente e a formação inicial: problematizando esta relação. In: REUNIÃO ANUAL DA ANPED, 27., 2004. Caxambu. Anais [...]. Caxambu, MG, 2004. Disponível em: http://27reuniao.anped.org.br/gt08/p083.pdf, Aceso em: 20 jun. 2015.

ROCHA, L. P.; FIORENTINI, D. O desafio de ser e constituir-se professor de Matemática durante os primeiros anos de docência. In: REUNIÃO ANUAL DA ANPED, 28., 2005. Caxambu. Anais [...]. Caxambu, MG, 2005. Disponível em: http://28reuniao.anped.org.br/. Acesso em: 30 mar. 2015.

SILVA, M. M. da.; CEDRO, W. L. O planejamento compartilhado das ações pedagógicas: a aprendizagem da docência do professor de Matemática. In: REUNIÃO ANUAL DA ANPED, 37., 2015. Florianópolis. Anais [...]. Florianópolis, SC, 2015. Disponível em:

http://37reuniao.anped.org.br/wp-content/uploads/2015/02/Trabalho-GT19-4268.pdf. Acesso em: 01 out. 2015.

SOARES, M. T. C.; PINTO, N. B. A pesquisa em colaboração no processo de formação do professor que ensina Matemática nas séries iniciais do ensino fundamental. In: REUNIÃO ANUAL DA ANPED, 24., 2001. Caxambu. Anais [...]. Caxambu, MG, 2001. Disponível em: http://24reuniao.anped.org.br/tp1.htm\#gt19. Acesso em: 12 jun. 2015.

\section{Como referenciar este artigo}

CIRÍACO, Klinger Teodoro. MORELATTI, Maria Raquel Miotto. A produção da ANPED sobre professores iniciantes e grupos colaborativos em educação matemática. Revista on line de Política e Gestão Educacional, Araraquara, v. 24, n. 2, p. 536-553, maio/ago. 2020. eISSN: 1519-9029. DOI: https://doi.org/10.22633/rpge.v24i2.13228

Submetido em: 20/01/2020

Revisões requeridas: $18 / 02 / 2020$

Aprovado em: 21/03/2020

Publicado em: 09/04/2020 